\title{
HERMENÊUTICA E DESCONSTRUÇÃO: A CONCILIAÇÃO DE PAUL RICOEUR E A APORIA DE JACQUES DERRIDA'
}

\author{
Hermeneutics and deconstruction: the conciliation of Paul \\ Ricoeur and the aporia of Jacques Derrida
}

Hermenéutica y deconstrucción: la conciliación de Paul Ricoeur y la aporía de Jacques Derrida

Carlos Cardozo Coelho

\section{Resumo}

Este artigo pretende apresentar a diferença entre a hermenêutica e a desconstrução e mostrar a implicação de cada uma destas formas de entender o fenômeno do sentido na relação da filosofia com as outras "disciplinas" do pensamento. Para isso colocaremos dois pensadores em embate direto, a saber, Jacques Derrida e Paul Ricoeur. Enquanto Paul Ricoeur, com seu projeto hermenêutico, tenta encontrar uma (re)conciliação entre os diversos saberes das ciências humanas com a metafísica, em uma época em que o estruturalismo e a psicanálise emergiam e questionavam conceitos como "consciência" e "sentido", Jacques Derrida radicaliza esses movimentos de crítica que animavam as ciências humanas e tenta pensar para além dos conceitos tradicionais, propondo seus quaseconceitos e formulando sua gramatologia.

Palavras-chave: Hermenêutica. Desconstrução. Interdisciplinaridade. Ontologia.

\footnotetext{
O presente trabalho foi realizado com apoio da Coordenação de Aperfeiçoamento de Pessoal de Nível Superior - Brasil (CAPES) - Código de Financiamento 001.

2 Professor convidado e pós-doutorando da Pós-graduação em Filosofia da UERJ com bolsa da CAPES-PNPD, doutor em Filosofia pela PUC-Rio com estágio sanduíche na Université de Paris XNanterre la Défénse. https://orcid.org/0000-0001-7331-4009...Email: cardozocoelho@gmail.com.
} 


\begin{abstract}
This article intends to present the difference between hermeneutics and deconstruction, and to show the implication of each of these ways of understanding the phenomenon of the meaning in the relation of philosophy to the other "disciplines" of thought. For this we will put two thinkers in direct confrontation, namely the thoughts of Jacques Derrida and Paul Ricoeur. While Paul Ricoeur, with his hermeneutic project, tries to find a (re) conciliation between various knowledge of the human sciences with the metaphysics, at a time when structuralism and psychoanalysis emerged and questioned concepts such as "consciousness" and "meaning", Jacques Derrida radicalizes these movements of criticism that animated the human sciences and tries to think beyond the traditional concepts, proposing his almostconcepts and formulating his grammatology.
\end{abstract}

Keywords: Hermeneutics. Deconstruction. Interdisciplinarity. Ontology.

\title{
Resumen
}

Este artículo pretende presentar la diferencia entre hermenéutica y deconstrucción y mostrar la implicación de cada una de estas formas de entender el fenómeno de sentido en la relación de la filosofía con las otras "disciplinas" del pensamiento. Para esto, ponemos dos pensadores en enfrentamiento directo, el pensamiento de Jacques Derrida y Paul Ricoeur. Mientras que Paul Ricoeur, con su proyecto hermenéutico, intenta encontrar una (re)conciliación entre los diversos saberes de las ciencias humanas con la metafísica, en un periodo en que el estructuralismo y la psicoanálisis surgieron y cuestionaron conceptos como "consciência" y "sentido", Jacques Derrida radicaliza estos movimientos de crítica que infundian vigor a las ciencias humanas e intenta pensar más allá de los conceptos tradicionales, proponiendo sus casiconceptos y formulando su gramatología.

Palabras clave: Hermenéutica. Desconstrucción. Interdisciplinaridad. Ontología.

\section{Introdução}

O presente trabalho busca estabelecer a comparação entre hermenêutica e desconstrução partindo da ideia de que ambas são herdeiras de uma tradição muito próxima, mas estabelecem duas formas muito distintas de construção conceitual (quaseconceitual no caso de Derrida). Tanto Ricoeur quanto Derrida começaram suas carreiras filosóficas se debruçando sobre o pensamento de Husserl, ambos estabelecem diálogo 
constante com Heidegger e, o mais importante para este artigo, eles sempre se colocaram em confronto com outras disciplinas do pensamento e posicionaram sua filosofia diante delas: da psicanálise à antropologia, do direito à política, da linguística à literatura, etc. Mas o filósofo magrebino e o hermeneuta francês não estavam em acordo, eles possuem posições radicalmente distintas em relação a estas disciplinas.

Ricoeur [1969], como veremos, traz a ideia de conciliação entre as diferentes disciplinas, ele vê a filosofia como aquela que é capaz de arbitrar a relação entre as diferentes ciências e estabelecer o campo de atuação de cada uma delas. Por exemplo, quando Saussure (1972) tenta pensar o signo para além da estrutura representativa da linguagem e fundar uma semiologia, pensar não mais o signo como signo de um referente, de uma realidade, mas enquanto uma oposição imanente interna ao sistema, Ricoeur [1969] vai considerar isso como um gesto antimetafísico, e vai mostrar que falta, ao pensamento de Saussure, semântica, que é a ciência da frase, e hermenêutica, uma ciência dos textos e das construções mais longas que os textos, em que esse enraizamento do signo na realidade se daria, e, com isso, o retorno de toda a estrutura da representação. $\mathrm{O}$ campo de validade da semiologia se concentraria nas estruturas inconscientes, mas a aplicação dela para campos como o de uma frase, por exemplo, geraria bizarrias, segundo Ricoeur [1969], pois para tanto precisaríamos de outra ciência, a saber, da semântica. O mesmo ocorre, por exemplo, quando o hermeneuta tenta segmentar a psicanálise a um discurso de força (uma energética pulsional inconsciente) e à hermenêutica (campo da análise do sentido e da atualização dessas forças), separando para o inconsciente um espaço restrito, espaço esse que não colocaria em xeque a fenomenologia e faria que ambas as disciplinas convivessem pacificamente.

Já a desconstrução derridiana propõe com seus quaseconceitos uma interdisciplinaridade mais radical, a tal ponto que os limites entre as diferentes disciplinas se tornam menos demarcados como na hermenêutica ricoeuriana. A relação de Derrida (1967) com as ciências é menos de separação e mais de radicalização dos aspectos de "crítica" e de descons- 
trução que elas trazem. Saussure, para Ricoeur, enquadrou o signo em sua estrutura de imanência e não mais como representação. Em relação a isso, Derrida vai mostrar, como veremos, que, o conceito de signo trouxe alguns avanços em relação à tradição, mas que ele ainda carrega em si diversas características clássicas à metafísica da presença e à representação, como, por exemplo, o privilégio da fala em detrimento da escrita. Derrida, a partir desse movimento, vai radicalizar tal desconstrução que começa com Saussure, a tal ponto que toda implicação metafísica do conceito de signo se esgote. Vale lembrar, como também será explanado, que não há "fora da metafísica", mas há desconstruções constantes da metafísica que provocam novas oposições, as quais vão reorganizar nosso mundo, mas serão também desconstruídas, etc.

Seguindo esse caminho, que consideramos rico, apresentaremos num primeiro momento a hermenêutica de Ricoeur, depois mostraremos como se constrói a desconstrução derridiana para, posteriormente, colocar esses dois pensamentos em choque.

Sigamos para o texto.

\section{A hermenêutica de Paul Ricoeur}

Paul Ricoeur, no seu livro O conflito das interpretações (s/d) busca enfrentar o desafio semiológico imposto pelas ciências humanas, nomeadamente, o desafio imposto pela psicanálise (com o seu conceito de inconsciente pulsional) e pelo estruturalismo (com o seu conceito de inconsciente estrutural) ao colocarem em xeque conceitos como consciência, sentido, etc., e demonstrarem que por trás desses conceitos presumidos como fundamentais e originários existem estruturas, sejam elas formais ou pulsionais, que os condicionam. Como afirma Claude Lévi-Strauss em um debate público com Paul Ricoeur organizado pela revista Esprit (1963): "Por trás de todo sentido há um não sentido, e o contrário não é verdadeiros".

Segundo o hermeneuta francês, a fenomenologia mantém três teses que a unificam: 1) a significação é a categoria mais englobante de toda 
a descrição fenomenológica; 2) o sujeito é o portador de significações; 3) é a redução transcendental, isto é, aquela colocada entre parênteses do mundo e que tem a afirmação da consciência como absoluto, que possibilita o nascimento de um ser para o campo das significações, ou seja, que permite que todo ser se apresente à descrição como fenômeno, como aparecer, logo, como significação a explicitar.

Desta forma, Freud, Marx e Nietzsche, tidos como os mestres da suspeita, aqueles que vislumbram um sentido oculto por trás de todo sentido manifesto, juntamente com Saussure e Lévi-Strauss, principais expoentes do estruturalismo, instauraram um novo paradigma de pensamento e impuseram um desafio à fenomenologia ao apresentarem algo que opera num nível anterior ao domínio da própria consciência, e que está fora do alcance do campo das significações. É esse desafio que nosso hermeneuta tenta dar conta.

No lugar de ignorar os mestres da suspeita que cresciam de influência tanto na filosofia quanto nas ciências humanas em geral, Ricoeur por toda sua obra vai tentar englobar este pensamento crítico no seu projeto ontológico. Na verdade, o filósofo se esforçará para arbitrar a relação das ciências humanas com a filosofia, pois para ele o papel da filosofia diante dessas questões é justamente o papel de árbitro e de mediador. Para Ricoeur (s/d), ao pensar sobre o ser, sobre a verdade e sobre o fundamento, a filosofia é aquela capaz de delimitar o campo de validade de cada pensamento e saber qual a aplicação adequada de cada método. Assim, podemos dizer que o pensamento de Ricoeur se ajusta perfeitamente ao aspecto interdisciplinar demandado hoje nos diversos segmentos da sociedade. Ao tentar conciliar psicanálise, linguística, antropologia, etc. com a filosofia, o pensador funda um pensamento que dialoga a todo instante com outras áreas de pensamento e, mais do que isso, faz desse diálogo uma condicional de qualquer tipo de reflexão sobre o ser: o filósofo deve fazer o détour pelas ciências para poder compreender de maneira mais própria aquilo que é a existência. Vejamos como se constrói esse pensamento. 
No interior desse projeto, Ricoeur [1969] propõe o enxerto da hermenêutica no interior do campo fenomenológico. A hermenêutica, que vira verdadeiramente um ramo da filosofia com Schleiermacher, se propõe a responder uma questão: o que é a compreensão? A partir dessa questão a hermenêutica se constituiu não apenas como uma disciplina que trata da interpretação de textos, mas também como uma disciplina epistemológica que tenta diferenciar as ciências do espírito (Geisteswissenschaften) das ciências da natureza para usar a terminologia de Dilthey (1988).

Para o filósofo francês, todos os textos que são objetos de interpretação são polissêmicos e, por isso, demandam inevitavelmente uma análise a partir da teoria dos signos e das significações. Ou seja, todos os textos têm vários sentidos

\footnotetext{
Se um texto pode ter vários sentidos [...], é preciso recorrer a uma noção de significação muito mais complexa do que a dos signos ditos unívocos que uma lógica da argumentação requer [...]. Por consequência, a hermenêutica não poderia permanecer uma técnica de especialistas [...], ela põe em jogo o problema geral da compreensão. Tanto mais que nenhuma interpretação notável pode constituir-se sem pedir empréstimos aos modos de compreensão disponíveis numa dada época: mito, alegoria, metáfora, analogia, etc. (RICOEUR, [1969], p. 6).
}

Podemos afirmar que é com Dilthey (1988) que a hermenêutica passa a ser uma disciplina não apenas interpretativa, mas epistemológica, pois "o problema de Dilthey era dar às Geisteswissenschaften uma validade comparável a das ciências da natureza, na época da filosofia positivista" (RICOEUR, [1969], p. 7). A filosofia de Dilthey (1988) surge, nesse contexto, contra o positivismo hegemônico da época - hegemônico a tal ponto que se infiltrava nas próprias ciências do espírito -; e, por isso, Dilthey (1988) reivindicou a hermenêutica, por ter como finalidade pensar a compreensão e apontar e instaurar os limites e distinções entre estes dois campos de pensamento. Em função disso, Dilthey (1988) faz uso da distinção entre explicação e compreensão para tentar mostrar as duas dinâmicas que estão em jogo nas ciências 
da natureza em oposição às ciências do espírito. Segundo o pensador alemão, explicamos um fato pelas suas causas, e o compreendemos pelo seu sentido, o qual não podendo ser positivamente observado, é apenas vivido.

Por mais que consigamos explicar as causas de determinada obra do espírito (um romance, um quadro, uma música, etc.), nunca seremos capazes de compreender os sentidos que estão em jogo em tal obra. Pensemos numa partida de futebol que está se tornando cada vez mais física, estatística e técnica. Mesmo com todo o avanço técnico, econômico e tático dos esportes que gerou uma mudança no ritmo do jogo, e mesmo com toda a tecnologia que nos permite explicar a forma como as equipes jogam e se postam em campo, a condição atlética dos jogadores, os pontos fortes e os pontos fracos nos esquemas de cada equipe, mesmo que possamos reduzir todo o jogo a gráficos e à estatísticas, jamais conseguiremos explicar, pelas causas, o sentimento de um torcedor num estádio lotado quando o seu time vira um jogo decisivo aos 45 do segundo tempo, ou mesmo quando ele sofre uma derrota deste tipo. Como dissemos, o sentido para Dilthey é compreendido, não explicado pelas suas causas (Cf. JARDIM ANDRADE, 2008, p. 77-112).

Dilthey considera, então, que nas ciências da natureza é indispensável a abstração da experiência vivida, em suma, do sentido. Logo, para que tenhamos uma explicação do jogo de futebol, temos que excluir todos os afetos envolvidos nele, devemos esquecer de toda relação histórica que uma pessoa construiu com este esporte (se o avô a levava ao estádio quando criança, se teve um momento de emoção numa Copa do Mundo, etc.). Em contrapartida, para que a compreensão se dê, precisamos de todos os elementos históricos que constituíram aquele sentido, ou melhor, o sentido é o nosso farol.

Tornamo-nos mestres deste mundo físico estudando as suas leis. Estas só podem ser descobertas na medida em que o caráter vivaz de nossas impressões da natureza, o conjunto que formamos com ela enquanto somos, nós mesmos, natureza e o sentimento vivo no qual a desfrutamos, cedam cada vez mais lugar à apreensão abstrata segundo as relações do espaço, do tempo, da massa, 
do movimento. Todos esses momentos concorrem para que o homem se elimine a si mesmo, a fim de construir, a partir de suas impressões, este grande objeto que é a natureza como uma ordem regida por leis. Esta ordem se torna, em seguida, para o homem, o centro da realidade (DILTHEY, 1988, p. 31).

Um procedimento como esse não é possível nas ciências do espírito pelo fato delas serem históricas e estarem enraizadas na experiência vivida. A distinção dilthyneana entre o fato vivido e o fato natural fundou exatamente a oposição entre explicação e compreensão: a explicação é o procedimento metodológico empregado pelas ciências da natureza, e, a compreensão, o empregado pelas ciências humanas. Como afirma um famoso aforismo de Dilthey: "Explicamos a natureza, compreendemos a vida psíquica” (DILTHEY, 1947, p. 150).

É nesse movimento de inspiração de Dilthey que Ricoeur vai tentar realizar o "enxerto do problema hermenêutico no método fenomenológico" (RICOEUR, [1969], p. 5). No entanto, ao contrário de Dilthey, ele não vai pensar que há uma oposição radical entre explicação e compreensão, mas vai entendê-los como dois movimentos complementares. Mas deixemos isto em suspenso por alguns instantes.

Para o pensador francês, Heidegger foi o primeiro a realizar tal enxerto, mas ele acabou adotando uma via curta, pois abriu rapidamente mão de uma reflexão sobre a técnica e método ao sobrevalorizar uma compreensão ontológica dada, inicial, e não mais como algo que se conquista. Nesse sentido, Heidegger, para Ricoeur, daria continuidade ao movimento de oposição radical entre explicação e compreensão e não os pensaria como complementares. O grande exemplo disso é o pensamento de Gadamer, que tenta dar continuidade à hermenêutica heideggeriana em seu Verdade e Método, que, segundo Ricoeur, deveria se chamar "Verdade ou Método"3.

\footnotetext{
3 O título da obra [Verdade e Método] confronta o conceito heideggeriano de verdade com o conceito diltheyano de método. A questão está em saber, então, até que ponto a obra merece chamar-se: Verdade E método, e se não deveria, antes, intitular-se: Verdade OU método (RICOEUR, 1986, p. 103).
} 
Ricoeur reconhece a suma importância da reflexão de Heidegger e a superação que ele faz do pensamento de Dilthey ao fazer este enxerto e pensar o Dasein como um ser que existe ao compreender, ou seja, a compreensão não é mais um modo de conhecer a nossa história, que nos constitui, mas ela é o próprio primado e constitutiva daquilo que somos. Ricoeur concorda e subscreve o conceito heideggeriano de Dasein, mas vê nele ainda uma forma simples de lidar com o problema da hermenêutica, pois essa forma de compreensão ignoraria os avanços das ciências humanas, e, segundo este filósofo, o détour pelas ciências humanas pode enriquecer nossa compreensão de nós mesmos.

Ao contrário de Dilthey (1988), o motivo de Heidegger propor o enxerto da hermenêutica na fenomenologia não é dar às ciências do espírito um método que se oponha ao das ciências da natureza, pois essa empreitada estaria ainda vinculada a uma estrutura de pensamento que reflete sobre o domínio da teoria kantiana do conhecimento e da oposição entre sujeito e objeto. O Dasein, para Heidegger, é uma forma de sair desta dualidade metafísica.

(...) é preciso sair deliberadamente do círculo encantado da problemática do sujeito e do objeto, e interrogarmo-nos sobre o ser. Mas, para nos interrogarmos sobre o ser em geral, é preciso primeiro interrogarmo-nos sobre este ser que é o "aí" de todo o ser, sobre o Dasein [ser-aí], isto é, sobre este ser que existe no modo de compreender o ser (RICOEUR, [1969], p. 9).

O caminho adotado por Heidegger abre espaço para o pensamento de Paul Ricoeur, mas certamente não é o mesmo que toma o pensador francês. Enquanto Heidegger separaria a compreensão e a explicação, Ricoeur formula uma ontologia militante, mediada pela interpretação dos signos e símbolos de nossa cultura. Ontologia militante porque ela está sempre em um movimento pendular, da compreensão para a explicação e da explicação de volta para a compreensão, movimento este interminável e inelutável. É nesse contexto que o filósofo propõe um enxerto da hermenêutica na fenomenologia de via longa. 
Assim, o método dessa "ontologia militante e fraturada" da via longa e não "triunfante", como a ontologia de Heidegger, que já tem a compreensão como uma conquista dada, seria o de articular explicação e compreensão como dois momentos de um mesmo processo.

Para uma exposição da dialética de explicação e compreensão enquanto fases de um único processo, proponho descrever esta dialética, primeiro, como um movimento da compreensão para a explicação e, em seguida, como um movimento da explicação para a compreensão. Da primeira vez, a compreensão será uma captação ingênua do sentido do texto enquanto todo. Da segunda, será um modo sofisticado de compreensão apoiada em um procedimento explicativo. [...] A explicação surgirá, pois, como a mediação entre dois estádios da compreensão. Se se isolar deste processo concreto, é apenas uma simples abstração, um artefato da metodologia (RICOEUR, 1995, p. 120).

Em síntese:

A procura de uma complementaridade entre estas duas atitudes que a hermenêutica de origem romântica [Dilthey e Schleiermacher] tende a dissociar exprimirá, assim, no plano epistemológico, a reorientação da hermenêutica (RICOEUR, 1986 , p. 83) $)^{4}$.

Ou ainda, como nos apresenta Daniel Desroches,

o grande desafio de Ricoeur é reconciliar, arbitrar ou praticar uma mediação entre as partes e o todo, o sujeito e seu objeto, a doação

\footnotetext{
4 Como se vê, ao criticar Dilthey, Ricoeur propõe um diálogo entre a compreensão e a explicação no âmbito das ciências humanas. No seu entender, essas ciências não são apenas compreensivas, mas também explicativas. Porém, considerando-se os estudos mais recentes da epistemologia diltheyniana, em particular a obra Dilthey el la fondation des sciences historiques (Paris: Puf, 1990), de Sylvie Mesure, tais críticas podem ser consideradas como improcedentes, pois esta relação de complementaridade entre explicação e compreensão já era defendida por Dilthey, sobretudo na segunda fase de sua reflexão epistemológica. Cf. Jardim Andrade, no artigo "Compreensão e explicação nas ciências do espírito: a epistemologia de Wilhelm Dilthey".
} 
e a apropriação, o método e a verdade, o signo e a significação, o distanciamento e o pertencimento, a explicação e a compreensão, a crítica e a convicção (DESROCHES, 2002, p. 9).

E acrescentamos: o estruturalismo e a hermenêutica, a semiótica e a semântica, o sistema e o discurso, em suma, o que a hermenêutica de Ricoeur faz é tentar mediar e reunir as aporias que se apresentam ao pensamento; este é o caminho da via longa da compreensão, este é, resumidamente, o caminho da hermenêutica ricoeuriana que pode ser chamada de uma epistemologia da interpretação. Já podemos adiantar que a diferença entre desconstrução e hermenêutica e dará no instante em que Ricoeur tenta reunir e findar as aporias e Derrida tentar mostrar que o que há é a própria aporia.

Nesse movimento é possível resumir a via adotada pelo francês com uma frase: explicar mais para compreender melhor. Ou seja, o pensamento de Ricoeur e a relação da filosofia com as outras disciplinas (sejam elas de "pensamento" ou meramente "técnicas", sejam elas explicativas ou compreensivas) é absolutamente interdisciplinar, mas toda a interdisciplinaridade deve passar pelo crivo e pela arbitragem da filosofia, que determina os campos de validade de cada uma das ciências.

Agora vejamos como Derrida e um pensamento que siga a linha da desconstrução abordam esta questão.

\section{A desconstrução de Jacques Derrida}

A necessidade que Derrida mostrará em Gramatologia de se buscar uma nova maneira de expressar o que seria esta linguagem, de se falar uma (na verdade, mais de uma) língua nova, e não apenas de substituir o significante "significante" por outro significante que signifique a mesma coisa, é o que faz o filósofo romper com a língua da metafísica e buscar novos termos, como, por exemplo, em detrimento de os conceitos que indicam quase-conceitos e indecidíveis. Entretanto, não se trata de abandonar a língua da 
metafísica em busca de uma língua originária, original, nem fundamental; tampouco uma 'nova' língua, uma língua do 'fora', mas de uma língua sempre "estranha", sempre "estrangeira", uma língua que tenha na ressignificação, na remarcação, esta estrangeiridade (HADDOCK-LOBO, 2008, p.6o).

Começaremos pelo debate em torno do livro De la grammatologie, que é considerado o grande texto de Derrida, e no qual toda a problemática sobre a linguagem se apresenta e é construída de maneira paradigmática. Esta obra aponta e critica a centralidade da discussão que predominava na época acerca da linguagem.

Como é notório na filosofia, a questão da linguagem é o tema central do século XX; tempo em que Derrida desenvolveu sua filosofia, e que, em alguma medida, foi - e vai - na contramão das teorias que instauraram a fala, a phoné, mais do que a própria linguagem em geral, como modelo fundamental daquilo que é o homem, teorias essas que afirmam que tudo o que há no mundo se apresenta a nós como linguagem - e a linguagem sempre encontrando seu lugar mais originário na fala.

No começo da sua gramatologia, em que ele tenta pensar uma ciência do grama no lugar de uma semiologia, a ciência do signo, Derrida (1967) nos conduz a pensar que o próprio signo "linguagem" (e, por conseguinte, o próprio conceito de signo) não consegue mais abarcar aquilo que pretendia inicialmente. Como mostra o filósofo, hoje em dia falamos de diversas linguagens para além da linguagem humana, desde a linguagem da matemática, a linguagem dos corpos, a linguagem dos genomas, a linguagem científica; chegamos mesmo a falar sobre a linguagem dos mortos, a linguagem dos animais, a linguagem de Gaia e do Sistema Terra, a linguagem da natureza e do universo, etc. Nesse movimento acabamos por generalizar este conceito de tal forma que ele não é capaz de dar conta daquilo que pretendia definir inicialmente. Em síntese, nos tempos em que Derrida escreveu a sua gramatologia havia uma crença pelo senso comum e que tudo o que existe no mundo possuía, em alguma medida, a 
sua própria linguagem, e não apenas uma linguagem no sentido de posse, mas enquanto maneira própria de ser de cada ente, de cada vivente.

Esta inflação do signo linguagem e do próprio conceito de signo apontada pelo filósofo mostra que esse pensamento acerca da linguagem, que privilegiava o homem como detentor dela, se encontra no interior de um processo de desconstrução, e mostra que ela, que centralizava os debates, não daria mais conta de responder as demandas daquele tempo. Por isso, o filósofo propõe a substituição do signo, que está atrelado à ideia de voz e de fala humanas, e que deve ser substituído pelo grama, pelo rastro, pelo traço, que são os quaseconceitos que colocam em xeque toda a estrutura metafísica da Origem (DERRIDA, 1967).

Aristóteles pensa a linguagem como uma estrutura hierárquica - a escrita para ele é a representação das palavras faladas que, por conseguinte, são a representação dos estados de alma, os quais representam, por sua vez, o plano das coisas, isto é, o plano ontológico ${ }^{5}$. Derrida tenta subverter esta lógica e pensar a escrita - isto que seria o mais distante do plano ontológico, e, por conseguinte, da Verdade - como aquilo mesmo que é a própria estrutura da existência: distância, espaçamento, différance. Dessa forma, enquanto para Aristóteles a fala teria uma proximidade maior com o plano das coisas, em Derrida a escrita (ou escritura, pois ambos são traduções possíveis do intraduzível écriture) sempre ficará rebaixada em comparação à fala, sempre julgada distante de uma presença, afastada da Verdade, considerada uma bizarria e perversão da voz humana, e é tomada como o movimento mais próprio do jogo do mundo.

Nas palavras do filósofo:

(...) não há dúvida de que o problema da linguagem nunca foi apenas um problema entre outros. Mas nunca, tanto como

\footnotetext{
5 Apenas os Estados de Alma e o Plano ontológico das coisas possuem uma relação de semelhança natural (de analogia), pois as coisas são infinitas e as palavras finitas. Entretanto, para Aristóteles, é possível dizer a verdade por meio da linguagem falada, desde que você siga as regras da razão. É por esta demanda de dizer a verdade mediante a linguagem que Aristóteles formulou a sua Lógica.
} 
hoje, invadiu como tal o horizonte mundial das mais diversas pesquisas e dos discursos mais heterogêneos em intenção, método e ideologia. [...] Esta inflação do signo "linguagem" é a inflação do próprio signo, a inflação absoluta, a inflação mesma. Contudo, por uma face ou sombra sua, ela ainda faz signo: esta crise é também um sintoma. Indica, como que a contragosto, que uma época histórico-metafísica deve determinar, enfim, como linguagem, a totalidade de seu horizonte problemático (DERRIDA, 2006, p. 7).

\section{E continua Derrida:}

(...) a linguagem mesma acha-se ameaçada em sua vida, desamparada, sem amarras por não ter mais limites, devolvida à sua própria finalidade no momento exato em que seus limites parecem apagar-se, no momento exato em que o significado infinito que parecia excedê-la deixa de tranquilizá-la a respeito de si mesma, de contê-la e de cercá-la (DERRIDA, 2006, p.7).

Assim, diante dessa questão que se instaura ao pensamento da desconstrução, Derrida crê que é necessário pensar não mais a linguagem enquanto Origem, isto é, enquanto fundamento de toda a existência e de toda condição de possibilidade do pensamento, mas mostrar que a linguagem não passa de um suplemento, de uma "estrutura" entre outras "estruturas" que estão sempre prestes a se desfazer, e que nada tem a ver com o conceito tradicional de Verdade - ou de Presença.

De acordo com o magrebino, o signo é sempre signo de, isto é, ele significa algo, aponta para um referente, para uma realidade; ele sempre é um movimento de se exteriorizar em direção a um significado transcendental que pararia toda a cadeia de sentido e o ancoraria num sentido fixo e final: em suma, significar é "dizer algo de alguma coisa"; o que está em jogo é sempre um ideal de presença, um significado transcendental.

Como explicita Roman Jakobson, a concepção estruturalista de signo retoma a distinção estoica, e depois escolástica, entre signans (que segundo 
Jakobson seria o significante de Saussure) e signatum (que nas palavras do mesmo seria o significado saussuriano), dando eco às oposições binárias da tradição metafísica e ontoteológica, e ao seu etnologocentrismo (Cf. DERRIDA, 2006, p. 24).

Contudo, apesar disso o pensamento de Saussure nos mostrou também que no interior de um sistema um signo não significa, isto é, ele não é signo de, ele não remete a nada de fora do sistema mas apenas a outros signos no interior do próprio sistema. Um signo não tem um sentido (não se direciona para fora do sistema para um significado transcendental), mas ele vale em oposição aos outros signos do sistema. Quando falo "cadeira" e atualizo o sistema da língua portuguesa, não me refiro ao objeto material "cadeira", mas a outros signos no interior do sistema como "sofá", "poltrona", "banco" e a partir da oposição dos signos entre si que surge o seu valor. O signo não possui um valor positivo, mas apenas opositivo, diferencial no interior da imanência do sistema. Nesse movimento, a distinção entre significante e significado introduzida por Ferdinand de Saussure, enquanto forma fônica e semântica no interior de um sistema diferencial de signos, abriu espaço para Derrida, e também para Lacan, pensarem o significado - por ser uma unidade meramente formal e não uma unidade sensível - como um significante colocado em uma posição privilegiada. Todavia, as posições de Derrida e de Lacan em relação a essa teoria são diversas e distintas, e cremos que a exposição dessas diferenças pode esclarecer a substituição do conceito de signo pelo quaseconceito, rastro que Derrida empreende.

Como nos mostra Jean-Luc Nancy e Philippe Lacoue-Labarthe, Lacan fez uma crítica ao pensamento de Saussure ao substituir o conceito de signo pelo conceito de algoritmo, conceito este que para Lacan não implica necessariamente um significado, mas, sim, que o signo saussuriano é indissociável da distinção entre significante e significado. Como afirmam Jean-Luc Nancy e Philippe Lacoue-Labarthe, ao comentarem sobre a teoria lacaniana do significante: 
O algoritmo não é o signo. Ou melhor: o algoritmo é o signo enquanto não significa (sobre o modo da representação do significado pelo significante). Poder-se-ia talvez arriscar a escrever: o algoritmo é o signo (cancelado). Signo sob canceladura de preferência a signo destruído (NANCY; LACOUE-LABARTHE, 1991, p. 47).

Contudo essa rasura que Lacan estabelece no interior do signo linguístico, que se apresenta com o silêncio do significado, não é absoluta. Ao embaralhar e riscar o pensamento saussuriano trocando o signo pelo algoritmo, e ao propor esta lógica do significante, Lacan coloca um termo (o algoritmo) - incomunicável na vida linguística, mas que opera no interior do sistema - como privilegiado e desta forma ele acaba ocupando o papel de centro de toda a cadeia dos significantes.

Em cima desta determinação do jogo dos significantes como relação dos buracos do sentido, vem enxertar-se uma determinação última a partir da qual ordena-se, de fato, o jogo no seu conjunto. Um significante a que Lacan dá o nome de o significante de uma falta no Outro. [...] Ele é o significante da própria falta de um símbolo (e de Deus?), a partir do qual articula-se a cadeia dos significantes. É o significante "sem o qual todos os outros nada significariam", puro desvio do significante em geral (NANCY; LACOUE-LABARTHE, 1991, p. 56).

Nesse movimento, no interior desse algoritmo, o significante enviaria a um significante que ocuparia função de significado. Assim, a conclusão de Nancy e de Derrida acerca da teoria de Lacan é que este significante de uma falta no Outro (-1) acaba se colocando como um significante-significado, dando sentido a toda a estrutura, e, portanto, reproduziria, ainda, uma estrutura de presença e de origem, estrutura esta que se vincularia ao que Derrida chama de metafísica da presença.

Tentando continuar o movimento de desconstrução, iniciado por Lacan e que já estava em curso no conceito saussuriano de signo, o filósofo magrebino tenta, na sua gramatologia, substituir o conceito de signo pelo 
quaseconceito trace (traduzido usualmente por rastro), que é aquilo que nunca se presentará, pois o significante estaria desde o "início" lançado numa rede diferenças de remetimentos infindáveis, na qual não há sentido, mas apenas efeitos. Essa rede de diferenças que não possui origem e nem significante último, Derrida vai chamar de différance, substituindo o e da palavra francesa différence (diferença em francês) pelo $a$, criando um quaseconceito, que, ao ser pronunciado na língua francesa, não possui nenhuma diferença sonora, pois esta só aparece na escrita. Dessa forma, o filósofo coloca em xeque o privilégio da fala que o conceito de signo carrega, e mostra que a ciência dos signos, a semiologia, deveria ser substituída por uma ciência do grama, uma gramatologia que seria regida pela différance, a diferença originária que corrompe com qualquer lugar de origem.

O quaseconceito rastro surge para mostrar que dizer que só há significante do significante é dizer que não existe significante, pois este é indissociável do significado, e que de fato só existe rastro. Seria um movimento de suplementar, de mostrar que um signo sempre remete a outro signo, que por sua vez remete a outro e, assim, essa cadeia segue sem fim, sem encontrar ancoragem em lugar algum, nem em um significante fálico, nem em um significado transcendental qualquer que seja. $O$ rastro surge como movimento de abolição da semiologia e instaura uma nova lógica, a lógica do suplemento, do grama, do rastro.

Lacan, ao manter seu conceito de algoritmo teria feito uma inversão do conceito de signo, mas teria esquecido de deslocar a estrutura. $\mathrm{O}$ próprio movimento da desconstrução seria o movimento de inverter e deslocar; a mera inversão de uma estrutura (afirmação do significante em detrimento do significado) a recolocaria ela de volta na afirmação de um dos polos, e a manteria no interior da metafísica. Para "sair" dela, ou construir uma nova estrutura a partir da desconstrução dos modelos antigos, é preciso deslocar, isto é, criar novos conceitos. O rastro não é, nesse sentido, nem significante, nem significado.

(Já aparece aqui algo que será importante na nossa conclusão: o caráter hiperbólico e indissociável da tradição que move a desconstrução. Não 
há fora da metafísica, a desconstrução opera sempre de dentro de um pensamento [ou nas margens dele] de maneira autoimune; ela é como uma autodesconstrução de um sistema em nome de uma heterogeneidade mais ampla, que é denegada pela fixação de qualquer tipo de estrutura ou constructo existencial. A desconstrução, no lugar de instaurar uma mediação entre as ciências e a filosofia, como faz a hermenêutica de Ricoeur, tenta levar o processo de fragmentação de um sistema ao seu limite para que algo surja e o processo da existência siga seu curso, contra qualquer tipo de pensamento que pretenda fixar uma Verdade ou um modo de existência determinado e indesconstrutível. A desconstrução é a alteridade se voltando contra a mesmidade.)

O psicanalista francês, coloca o falo na ordem simbólica (não é um falo real, nem imaginário) e o apresenta como falta, pura negação. Entretanto, Lacan o posiciona como um transcendental que direciona e conduz todo o jogo dos significantes. Já a desconstrução de Derrida nos parece mais radical: ela radicaliza tanto o signo linguístico quanto o algoritmo psicanalítico, e contamina a filosofia e seu caráter metafísico com o diálogo com esses pensamentos - e esse é o próprio movimento da desconstrução na sua relação com as diferentes ciências, como veremos no final deste texto. Como afirma Derrida,

não há significado que escape, mais cedo ou mais tarde, ao jogo de remessas significantes, que constitui a linguagem. $O$ advento da escritura é o advento do jogo; o jogo entrega-se hoje a si mesmo, apagando o limite a partir do qual se acreditou poder regular a circulação dos signos, arrastando consigo todos os significados tranquilizantes, reduzindo todas as praças-fortes, todos os abrigos do fora-do-jogo que vigiam o campo da linguagem. Isto equivale a destruir o conceito de "signo" e toda a sua lógica (DERRIDA, 2006, p. 8).

A desconstrução é esse movimento do pensamento que mostra o funcionamento do jogo do pensamento metafísico que sempre busca 
instaurar uma presença e origens. O filósofo que se orienta no interior da desconstrução é aquele que tem "consciência" da temporalidade das compreensões de mundo, pois, por mais que as pessoas tenham a crença ou vivam como se existisse apenas um mundo, a regra da existência para o pensador da desconstrução é que há uma pluralidade incontável de razões a respeito do mundo, que ele é sempre mais de um.

É por isso que Derrida se volta para expressões como escrita em oposição à fala, animal em oposição à homem, sentido metafórico em oposição à sentido próprio. Todas essas expressões, por serem tomadas pela tradição como secundárias, suplementares (ou seja, como o significante de significante), acabam representando o funcionamento absoluto do mundo (a suplementaridade passa a ser ponto de partida, subvertendo assim a lógica da metafísica da presença), pois "la chose même se dérobe toujours" [a coisa mesma sempre escapa] (Derrida, 1994, p. 117), e essa é a estrutura mais própria do mundo e da realidade: o movimento do escapar.

Aparece aí, então, uma espécie de elogio à escritura (como trace) em oposição a uma linguagem original que presentificaria um significado transcendental, um sentido que direcionaria o homem para alguma ancoragem. A escritura é então esse jogo de derivações, é suplemento da existência. É o movimento de inscrição e desinscrição constante de tudo que existe.

\section{Considerações finais: hermenêutica versus desconstrução}

Citemos uma passagem da discussão pública que Ricoeur teve com Derrida em 1967 no Canadá, em um colóquio sobre filosofia de língua francesa, para compreendermos o que está em jogo aqui:

P.R. [...] Então você é obrigado a sobrecarregar a teoria da escritura de tudo aquilo que não foi feito no seu lugar próprio, que é a teoria do discurso. Se esta teoria do discurso é um fato, ela pode dar conta das características da escritura que você mostrou, pois é na discursividade mesma que existem todos estes traços 
que você atribuiu à escritura. É um pouco sobre este problema que, da minha parte, gostaria de discutir com você.

J.D. Sem dúvida, entre outras lacunas, aquela de uma teoria do discurso é bem marcante, não apenas na exposição que eu fiz esta manhã, mas nas proposições que eu arrisquei anteriormente. $O$ que me interessa, de maneira preambular numa teoria do discurso que é, com efeito, totalmente necessária, o que me interessa, é marcar todos os pressupostos, não críticos, que me parecem carregar até aqui as tentativas de teoria do discurso as quais pudemos assistir mais na linguística que na filosofia. Estes pressupostos são aqueles que eu muito esquematicamente esbocei esta manhã, a saber, que alguma coisa como o acontecimento, por exemplo, que nós sabemos que era só um acontecimento; ora, uma teoria do discurso supõe uma teoria do acontecimento, teoria do ato, "speech act", teoria do ato como acontecimento singular, e sobre este conceito de acontecimento, por exemplo - mas este conceito de acontecimento faz esquema [eu devia ter dito "canal"] com todo um conjunto de outros conceitos - eu ensaiei marcar aquilo que impediria todo pretendido acontecimento (singular, atual, presente, insubstituível, irrepetível, etc.) de se constituir como acontecimento no sentido filosófico, isto é, aquilo que ramificaria a singularidade pelo simples fato que este acontecimento era um gênero de discurso, dissemos simplesmente um acontecimento semiológico e quando você diz que...

P.R. Não é a mesma coisa...

J.D. Sim, eu vou tentar...

P.R. É esta distinção do semiológico e do semântico [...].

J.D. Justamente... eu acabo.

P.R. Que me parece absolutamente fundamental...

J.D. Eu acabei...

P.R. E misturado numa teoria da escritura que é semiológica em muitos traços, mas quer resolver problemas da semântica com recursos semiológicos.

J.D. Sim, eu acabei neste ponto. De certa maneira, eu preciso, de maneira preambular, que isto que eu ensaio também é uma crítica 
da semiologia. Por consequência, me parece difícil de enclausurar isso que eu faço em semiológico [...] isso que eu tento fazer não é de todo reduzir o discurso a um conjunto de signos, porém evitar que esqueçamos que no discurso há ainda signo, isto é, com o signo o canal diferencial, o espaçamento, etc. É todo o que...

P.R. Sim, porém eu creio que necessitaríamos distinguir aquilo que entendemos por espaçamento. Não é o mesmo espaçamento que você tem na ordem semiológica, logo que um signo é distinto de outro signo: que isso seja um espaçamento fonético ou um espaçamento gráfico, é o espaçamento semiológico; mas no espaçamento do discurso, é totalmente outra coisa [...]. Logo que você disse: $O$ discurso é sempre tomado no signo, de acordo; porém ele pode mudar também de rede, é isso a tradução. Então o problema é saber o que traduzimos; o que traduzimos, é o sentido de um discurso. Você o fez passar de um sistema semiológico num outro sistema semiológico. O que é que se passa? São os traços do sentido. Porém, se você não tem uma teoria do sentido você não pode, não mais, fazer uma teoria da tradução.

J.D. Será que eu me engano ou você reservou a diferença ao semiológico como se não houvesse diferença semântica, como se o semântico não se constituísse de maneira diferencial?

P.R. Sim, porém eu não colocaria uma maiúscula no diferencial...

J.D. Você me reprova já faz um bom tempo de colocar uma maiúscula no diferencial... eu nunca a coloquei.

P.R. Porém com “a”...

J.D. Mas é outro sentido da palavra...

P.R. É outro sentido da palavra. Há diferença entre os signos, pois há o fato que o sujeito não é o predicado, enfim, há sobretudo diferenças; porém o que é importante é que o discurso produz pelas diferenças próprias que não são diferenças semiológicas, dos efeitos do discurso que não são efeitos de signos.

J.D. Eu estou completamente de acordo! É porque eu nunca disse que a diferença foi reservada ao elemento semiológico [...] ( DERRIDA, 2004, p. 33-36). 
Esta passagem é magistral para percebermos a falta de compreensão que sempre pairou nas discussões entre Ricoeur e Derrida. Ricoeur nunca conseguiu, realmente, captar o sentido da obra de Derrida (ou ao menos não neste momento, pois no final da vida, no último capítulo do seu livro de 2011 Vivo até a Morte, ele chega a dizer que a obra de Derrida é mais grandiosa que a sua, apesar das discordâncias em muitos pontos).

Ricoeur vê no conceito de différance um conceito maiúsculo que instauraria a diferença como absoluto (assim como o conceito heideggeriano de Ser seria, para Ricoeur, um conceito maiúsculo) e esqueceria do plano semântico, o plano do discurso, plano propriamente hermenêutico, no qual o signo se torna palavra em posição de fala, no interior de uma frase e em que há, para Ricoeur, o enraizamento na realidade. Entretanto, cremos que uma das finalidades de Derrida é acentuar a diferencialidade que há entre a fala e a escrita e que a escrita não é mera reprodução da fala, mostrar a diferença que opera tanto no interior das estruturas quanto nesse momento do discurso que seria o momento do querer dizer, e esta différance faz ver que este querer dizer não nos remete à nenhuma realidade em si ou que pare o processo de envio da linguagem, mas ela remete apenas a mais referências sem referente: rastros!

Não há diferença no evento da fala entre a palavra différence e o quaseconceito différance, pronunciamos ambos da mesma forma, assim, a fala silenciaria em determinados momentos a escrita, assim como a escrita silenciaria a fala em outros momentos. Para Derrida, a différance age em todos os níveis, sejam semióticos, semânticos, ou qualquer outro.

Ricoeur pensa em Derrida como um estruturalista que radicalizou o estruturalismo esquecendo-se do plano semântico. Entretanto, segundo a nossa interpretação, Derrida radicaliza o estruturalismo, mas de forma distinta. Esta radicalização consistiria não apenas em tornar o conceito de différance como um absoluto, mas também de aplicá-lo em outros planos que não o semiológico, como o plano semântico e a todos os campos de pensamento. Destarte, para o filósofo magrebino, o quaseconceito différance ocupa um importante papel, talvez ele seja mesmo (junto com o 
quaseconceito de escritura) o grande "conceito" de Derrida, o "conceito" que está presente em toda a sua obra, em toda a disseminação.

No artigo de Ricoeur intitulado "Langage", contido na Encyclopedie Universallis, na seção "o estruturalismo filosófico" e na subseção "o modelo do sistema sem coisa", o filósofo francês comenta brevemente a gramatologia de Jacques Derrida. Esta atitude de Ricoeur não representaria, de certa forma, uma maneira de pensar Derrida como um pensador inserido no interior do movimento estruturalista? A resposta para esta pergunta nos parece óbvia. Cremos que para pensar nessa filiação ao estruturalismo devemos partir da ideia de "hiper-radicalidade" (esse pensar para além) apontada por Fernanda Bernardo (2007, p.117-126) em diversos artigos e afirmada pelo próprio filósofo magrebino no seu livro O monolinguismo do outro:

Contraí na escola este gosto hiperbólico [...]. E, consequentemente, para a hipérbole em geral. Uma hipérbole incurável. Uma hiperbolite generalizada. Enfim, eu exagero. Eu exagero sempre (DERRIDA, 1996, p. 81).

Comentando esta passagem, Bernardo afirma:

[...] gosto que se traduz no hiperbolismo do seu passo/não-passo para além (pas au-delà) que revela a sua hiper-radicalidade como pensamento singularmente distinto da filosofia - uma hiper-radica-lidade que, notemo-lo também de passagem, assinala igualmente a diferença, reiteradamente reivindicada por Derrida, entre crítica e des-construção. Um passo/não-passo para além do mundo, do ser e do ser-no-mundo, numa palavra, para além do instituído, para além, portanto, da filosofia que é, ela, sempre do mundo (como aliás a ética, o direito, a política, a literatura, as artes, etc. ...). E é justamente este passo/não-passo para além - o passo para ou em direção ao "algures absoluto" do "outro absoluto", num dizer de Derrida de $O$ monolinguismo do outro - que dá conta do alcance hiper-ético (e hiper-racional, e hiper-político e hiper-poético) da desconstrução derridiana (BERNARDO, 2007, p. 118-119). 
Podemos ser levados a pensar que, talvez ${ }^{6}$ (e registra-se aqui o negrito/ grifo em talvez como forma hipercética ${ }^{7}$ de acentuar a dúvida), Derrida tenha conduzido esse movimento que teve seu início com Saussure até suas últimas instâncias, a saber, o afirmar da impossibilidade da referência a um significado transcendental, ou seja, o afirmar do jogo de remetimentos infindáveis do rastro que jamais conduz a algo como uma coisa mesma, mas apenas a mais rastros.

Como dissemos, Ricoeur prega, no decorrer de sua obra, uma complementaridade entre hermenêutica e estruturalismo (como também o faz com a psicanálise, a filosofia analítica e diversas outras áreas). Destarte, os métodos de Saussure e Lévi-Strauss não excluiriam os métodos de Dilthey e Schleiermacher. "A compreensão das estruturas", afirma Ricoeur, "não é exterior a uma compreensão que teria por tarefa pensar a partir dos símbolos; ela é hoje em dia o intermediário necessário entre a ingenuidade simbólica e a inteligência hermenêutica" ( $s / \mathrm{d}, \mathrm{p} .53)^{8}$. Como sintetiza o próprio filósofo, é preciso "fazer o rodeio da estrutura para reencontrar a significação" (RICOEUR, 1970, p. 119).

Na nossa interpretação, essa hiper-radicalidade do pensamento de Derrida aponta para um modo distinto de pensar a relação da filosofia com as outras áreas de conhecimento. No lugar em que Ricoeur coloca a filosofia

\footnotetext{
- Empregada inúmeras vezes em seus textos, a palavra "talvez", reflete uma postura característica do pensamento derridiano para o qual o seu correlato, o que é pensado, não se enquadra na oposição binária, metafísica, entre presença e ausência, entre ser e nada. A palavra "talvez" faz lembrar a inevitável precipitação do pensamento diante do caráter singular e, portanto, absolutamente outro, do que se dá a pensar. Ela faz lembrar que a relação do pensamento com o que é pensado - como, aliás, toda relação - é sempre e necessariamente uma relação de alteridade. Ao propor um compromisso incondicional com a alteridade, o pensamento derridiano sempre se desdobra segundo certa lógica do talvez (DUQUE-ESTRADA, 2010, p. 341).

7 Haddock-Lobo, no artigo supracitado (2009), tenta pensar uma possível herança cética no pensamento da desconstrução, herança esta que passaria pela relação que Derrida estabelece com a literatura. Indicando um caminho para que possamos pensar esse ceticismo, HaddockLobo ressalta dois termos como paradigmáticos na obra de Derrida: o "talvez" e o "como se".

8 Toda a estrutura de significação em que um sentido direto, primário, literal, designa, por acréscimo outro sentido indireto, secundário, figurado, que só pode ser apreendido por meio do primeiro", e ainda, "esta circunscrição das expressões com duplo sentido constitui precisamente o campo hermenêutico" (RICOEUR, s/d, p. 14).
} 
como a árbitra responsável por fazer a conciliação de diferentes campos de pensamento, delimitando cada uma ao seu próprio campo de validade (semiologia estuda os sistemas de signo; semântica o plano das frases; hermenêutica o campo dos conjuntos de frases, os textos, etc.), Derrida se apoia no choque metafísico que essas ciências, juntamente com os mestres das suspeitas, impuseram à filosofia, e tenta radicalizar esse choque, dar continuidade a ele e mostrar todas as implicações e desconstruções que estão em jogo nesse choque entre filosofia e ciências. No mesmo ponto em que Ricoeur tenta a conciliação, Derrida segue o caminho da aporia.

"Se côtoyer" (caminhar ao lado de; frequentar; relacionar-se com; ladear; bordejar; tocar), diz Ricoeur para exprimir sua relação filosófico-afetiva com Derrida que, por conseguinte, o complementa: "chassé-croisé" (contradança; jigajoga; vaivém) (DERRIDA, 2004, p. 2-39). De um lado Ricoeur segue no caminho de um pensamento conciliador e vê caminhos paralelos, já Derrida vê um cruzamento de caminhos opostos, até mesmo inconciliáveis. Ricoeur, nesse sentido, vê Derrida como um filósofo da suspeita e que lhe falta a confiança da compreensão hermenêutica; e já Derrida sabe que ambos partem de pontos de vistas absolutamente distintos e que não há mediação possível, mas apenas desconstrução.

Como dissemos, para o filósofo francês toda a filosofia da suspeita deve ser precedida e seguida por uma filosofia da confiança. Assim, Ricoeur propôs que a ontologia hermenêutica de Heidegger deveria se confrontar com aqueles pensadores que denominava mestres da suspeita, isto é, o pensamento de Heidegger deve ser confrontado com os pensamentos de Marx, Nietzsche e Freud (e, acrescentamos a eles o movimento estruturalista), para que uma nova ontologia surgisse a partir deste confronto: a via longa.

Neste sentido, Ricoeur, ao criticar a ontologia de Heidegger a partir do estruturalismo e da psicanálise, propôs uma ontologia que passa pelos signos e símbolos de nossa cultura, ontologia que ele denomina como militante, pois a compreensão ontológica não é mais um dado como em Heidegger, mas ela deve ser conquistada no embate com as filosofias 
da suspeita. Com esse movimento, Ricoeur conseguiria fazer com que as ciências da linguagem e a ontologia da compreensão convivessem pacificamente, cada disciplina ocupando seu lugar no pensamento e cada uma enriquecendo a outra - mas a distância.

Em termos derridianos, podemos dizer que toda a desconstrução acaba sendo precedida e seguida por uma construção que corre sempre o risco de se estagnar e ocupar um papel repressor, contudo só há desconstrução no interior deste movimento infinito, movimento que o filósofo magrebino chama de escritura. Para Derrida é a própria construção que gera - de maneira autoimune, do interior das construções - a desconstrução. Enquanto o francês tentava superar a suspeita em nome da confiança no Ser - e colocava a filosofia como a árbitra das outras ciências, Derrida nos mostra a desconstrução - herdeira direta dos mestres da suspeita - como movimento intrínseco ao pensamento, como algo que está sempre acontecendo, da mesma forma que estamos sempre construindo. É a desconstrução que nos mostra a parcialidade e provisoriedade destas construções, e, mais do que isso, ela mostra que toda construção nunca é primeira, toda construção já é uma "re-construção". Dessa forma, uma filosofia da confiança nunca seria capaz de superar a desconstrução, pois ela é o próprio movimento do pensamento - e do mundo.

Então, uma questão emerge: assim como toda filosofia da confiança vem após uma filosofia da suspeita, uma construção emerge após - e antes de - uma desconstrução. Essa nova filosofia da confiança deve ser também desconstruída, esse é o movimento infinito do pensamento. Logo, a filosofia da confiança que Ricoeur acreditava poder alcançar ao passar pelos signos e símbolos da cultura, se mostra como apenas uma nova clausura a ser desconstruída. Contudo, não podemos cair na armadilha de pensar que esse movimento é um movimento circular, linear ou cronológico; há, no interior do próprio movimento desconstrutivo um elã reconstrutivo implicado de maneira mais ou menos intensa.

Em suma, Ricoeur via conciliação e confiança, um retorno à ontologia a partir do diálogo com as ciências que aparentemente colocariam uma 
ontologia fenomenológica em xeque; e, Derrida, se engaja no interior desses movimentos e tenta fazer ecoar a desconstrução que eles trazem para a própria filosofia e para a metafísica da presença.

Temos duas maneiras distintas aqui de nos relacionarmos com o caráter interdisciplinar do pensamento: de um lado tentar fazer a filosofia renascer e absorver para si o direito de juíza das ciências, determinando campo de atuação para cada área de pensamento, e, de outro, um apagamento desses campos que nos conduziria a questionar a filosofia e o próprio pensamento na sua base metafísica. No momento em que os conceitos de signo e de inconsciente estrutural de Saussure apresentavam uma ameaça para a fenomenologia, Ricoeur os integra no interior do seu projeto hermenêutico como parte explicativa da compreensão; já Derrida radicaliza esta ameaça até que ela seja mais radical e imploda a própria metafísica, e com isso mostre a completa provisoriedade de qualquer estrutura de pensamento, e que a desconstrução é um movimento ininterrupto do pensamento e não acontece de maneira pendular como a dialética ricoeuriana ao tratar da questão que se encontra entre compreensão e explicação. Essa diferença repercute por toda a obra dos dois filósofos: Ricoeur estabelece diálogo com o direito, com a psicanálise, com o marxismo, com a filosofia analítica e sempre pensa a relação de sua hermenêutica com essas disciplinas de maneira conciliadora, enquanto Derrida, ao estabelecer diálogo ao longo de sua obra com todas tais "disciplinas" as coloca no movimento de desconstrução e as radicaliza para que elas contaminem a metafísica da presença.

Enquanto a hermenêutica de Ricoeur defende que a filosofia arbitre a relação entre as diferentes disciplinas de pensamento e se coloca como o espaço mais próprio para se pensar uma interdisciplinaridade - mas uma interdisciplinaridade que mantenha uma segmentação entre as diferentes disciplinas de pensamento -, a desconstrução exposta por Derrida pretende mostrar como a construção desses limites é artificial, e se utiliza de todas essas ciências para mostrar a desconstrução que opera no interior do pensamento e que eclode na filosofia. Que as diferentes disciplinas 
(seja a matemática, a literatura, a história, a biologia, etc.) se organizem de maneira distinta e tenham campos de atuação diferentes é um fato, que a filosofia se arrogue o papel de ser a gestora dessa relação é algo que realmente acontece, mas esses fatos não passam de constructos que estavam e continuam a desmoronar em nome de novas formas de organização, pois a própria filosofia enquanto filosofia do mesmo é colocada à prova pela desconstrução e pela alteridade.

\section{Referências}

BERNARDO, F. Verso para uma poética. Revista Filosófica de Coimbra, n. Coimbra, n. 31, p. 71-142, 2007.

CUISENIER, J.; RUWET, N.; GABORIAU, M.; RICOEUR, P. (Suivis d'une discussion avec Cl. Lévi-Strauss) La pensée sauvage et le sctructuralism. (Reponses à quelques questions). Esprit, Paris, número spécial, nov. 1963

DERRIDA, J. A escritura e a diferença. São Paulo: Perspectiva, 2009.

DERRIDA, J. De la Gramatologie. Paris: Minuit, 1967.

DERRIDA, J. Le monolinguisme de l'autre. Paris: Éditions Galilée, 1996.

DERRIDA, J. Marges de la philosophie. Paris: Minuit, 1972.

DERRIDA, J. La parole: donner, nommer, appeler. In: D'ALLONNES, Myrian Revault; AZOUVI, François. (org.). Cahiers de L'herne': Ricoeur 1. Paris: Éditions de L'Herne, 2004. p. 2-39.

DESROCHES, D. A via longa da compreensão em Paul Ricoeur. In: MARCONDES CESAR, C. (org.). A hermenêutica francesa: Paul Ricoeur. Porto Alegre: Ed. PUCRS, 2002. p. 9-26.

DILTHEY, W. L'Édification Du monde historique dans les sciences de l'esprit. Tradução e apresentação: Sylvie Mesure. Paris: Cerf, 1988. https://doi. org/10.4000/books.septentrion. 28623

DILTHEY, W. Le monde de l'esprit. Tradução: Louis Sauzin. Paris: Aubier; Montaigne, 1947. v. 2

HADDOCK-LOBO, R. Derrida e o labirinto de inscrições. Porto Alegre: Zouk, 2008. 
HADDOCK-LOBO, R. Considerações sobre um "hiperceticismo" em Jacques Derrida. In: PEREIRA, M. A.; FERREIRA SÁ, L. F. Jacques Derrida: atos de leitura, literatura e democracia. Belo Horizonte: Faculdade de letras da UFMG, 2009. p. 105-117. https://doi.org/10.17771/pucrio.acad.9799

HEIDEGGER, M. Ser e Tempo. Tradução: M. S. C. Schuback. Petrópolis: Vozes, 2006.

JARDIM ANDRADE, R. Compreensão e explicação nas ciências do espírito: a epistemologia de Wilhelm Dilthey. In: MIRANDA HÜHNE, L. (org.). Filosofia e Ciência. Rio de Janeiro: UAPÊ, 2008. p. 77-112.

JARDIM ANDRADE, R. Le structuralisme et la question du sujet: la formation du champ sémiologique. Lille: ANRT (Atelier National de Reproduction de Thèses), 2000.

JARDIM ANDRADE, R. O Modelo hermenêutico de reflexão: o diálogo entre filosofia e ciências humanas no pensamento de Paul Ricoeur. In: LORENZON, Alino; GÓIS E SILVA, Cléa (org.). Ética e Hermenêutica na Obra de Paul Ricoeur. Londrina: EDUEL, 2000. p. 215-226.

MESURE, S. Dilthey el la fondation des sciences historiques. Paris: PUF, 1990. NANCY, J.-L.; LACOUE-LABARTHE, P. O título da letra. Rio de Janeiro: Escuta, 1991.

RICOEUR, P. La métaphore vive. Paris: Le Seuil, 1975.

RICOEUR, P. A metáfora viva. São Paulo: Edições Loyola, 2000.

RICOEUR, P. De l'interprétation: essai sur Freud. Paris: Le Seuil, 1965.

RICOEUR, P. Discours et communication. Cahier de l'herne, Ricoeur 1, L'Herne, 2004.

RICOEUR, P. Du texte à l'action: essais d'herméneutique II. Paris: Le Seuil, 1986.

RICOEUR, P. Do texto à acção: ensaios de hermenéutica II. Porto: Rés-Editora, $\mathrm{s} / \mathrm{d}$.

RICOEUR, P. Écrits et conférences 2: herméneutique. Paris: Le Seuil, 2010.

RICOEUR, P. O conflito das interpretações: ensaios de hermenêutica. Tradução: Artur Morão. Porto: Rés-Editora, [1969].

RICOEUR, P. Teoria da interpretação. Tradução: Artur Morão. Porto: Porto Editora, 1995. 
RICOEUR, P. Vivo até à Morte. Tradução: Hugo Barros e Gonçalo Marcelo. Lisboa: Edições 70, 2011.

SAUSSURE, F. Cours de linguistique générale (édition critique preparée par Tullio de Mauro), Paris: Payot, 1972.Recebido em: 30/6/2018 | Aprovado em: $6 / 2 / 2019$. 